\title{
Acute effects on metabolism and appetite profile of one meal difference in the lower range of meal frequency
}

\author{
Astrid J. Smeets ${ }^{1 *}$ and Margriet S. Westerterp-Plantenga ${ }^{2}$ \\ ${ }^{1}$ Department of Human Biology, Maastricht University, P.O. Box 616, 6200 MD, Maastricht, The Netherlands \\ ${ }^{2}$ Top Institute Food and Nutrition, P.O. Box 557, 6700 AN, Wageningen, The Netherlands
}

(Received 18 July 2007 - Revised 8 October 2007 - Accepted 25 October 2007 - First published online 6 December 2007)

A gorging pattern of food intake has been shown to enhance lipogenesis and increase body weight, which may be due to large fluctuations in storage and mobilisation of nutrients. In a state of energy balance, increasing meal frequency, and thereby decreasing inter-meal interval, may prevent large metabolic fluctuations. Our aim was to study the effect of the inter-meal interval by dividing energy intake over two or three meals on energy expenditure, substrate oxidation and $24 \mathrm{~h}$ satiety, in healthy, normal-weight women in a state of energy balance. The study was a randomised crossover design with two experimental conditions. During the two experimental conditions subjects (fourteen normal-weight women, aged 24.4 (SD 7.1) years, underwent $36 \mathrm{~h}$ sessions in energy balance in a respiration chamber for measurements of energy expenditure and substrate oxidation. The subjects were given two (breakfast, dinner) or three (breakfast, lunch, dinner) meals per d. We chose to omit lunch in the two meals condition, because this resulted in a marked difference in inter-meal-interval after breakfast $(8.5 \mathrm{~h} v .4 \mathrm{~h})$. Eating three meals compared with two meals had no effects on $24 \mathrm{~h}$ energy expenditure, diet-induced thermogenesis, activity-induced energy expenditure and sleeping metabolic rate. Eating three meals compared with two meals increased $24 \mathrm{~h}$ fat oxidation, but decreased the amount of fat oxidised from the breakfast. The same amount of energy divided over three meals compared with over two meals increased satiety feelings over $24 \mathrm{~h}$. In healthy, normal-weight women, decreasing the inter-meal interval sustains satiety, particularly during the day, and sustains fat oxidation, particularly during the night.

Fat oxidation: Satiety: Meal pattern

Obesity is a major cause of morbidity and mortality in Western societies. Fundamentally, obesity results from an energy imbalance that occurs when energy consumption exceeds energy expenditure. In order to achieve a state of energy balance, energy intake should meet and not exceed energy expenditure. In human individuals, energy intake is not fully adapted to energy expenditure when assessed per d, but does meet energy expenditure when assessed over 1 week $^{(1,2)}$. In Western populations, typically, three meals per $d$ are consumed, with the largest meal in the evening. Fabry and co-workers were the first to demonstrate an inverse relationship between habitual meal frequency and body weight in human subjects ${ }^{(3-5)}$. Later meal frequency studies have shown that nibblers, having a meal frequency of four or more meals/d, are able to compensate more accurately over $24 \mathrm{~h}$ for manipulation of the energy content of the foods consumed than meal feeders having a meal frequency of less than three meals $/ \mathrm{d}^{(6,7)}$. Increasing meal frequency has also been shown to sustain satiety ${ }^{(7)}$. Snack consumption, however, has been suggested to be a risk factor for obesity ${ }^{(8)}$. In a recent study, Stote and colleagues observed a significant reduction in body weight and body fat of subjects who consumed one meal per $\mathrm{d}$ for 8 weeks ${ }^{(9)}$. Chapelot and colleagues observed an increase in body fat and RQ when subjects who were used to consuming four meals per $\mathrm{d}$ switched to eating three meals per $\mathrm{d}$ for $28 \mathrm{~d}^{(10)}$. These relatively long-term studies showed different effects of reducing meal frequency on body fat. A gorging pattern of food intake has been shown to enhance lipogenesis and increase body weight, which may be due to large fluctuations in storage and mobilisation of nutrients. In a state of energy balance, increasing meal frequency, and thereby decreasing inter-meal interval, may prevent large metabolic fluctuations. To gain insight into a one meal difference in the lower range of meal frequency, we studied the acute effect of dividing energy intake over three or two meals per $d$ on energy expenditure, substrate oxidation and $24 \mathrm{~h}$ satiety in healthy, normalweight women in a state of energy balance. We chose to omit lunch in the two meals condition because this resulted in a marked difference in inter-meal interval. In the two meals condition, the inter-meal interval after breakfast is $8.5 \mathrm{~h}$. In the three meals condition, the inter-meal interval is $4 \mathrm{~h}$.

\section{Subjects and methods}

Subjects

Fourteen females (BMI 23.2 (SD 2.7) kg/m²; age 24.4 (SD 7.1) years; Three Factor Eating Questionnaire (TFEQ) F1 4 (SD 3); body fat 27.4 (SD 6.9) \%) were studied on three occasions. Sixteen women were initially selected based on age, height, weight, BMI and restrained eating score (F1 score) on the TFEQ ${ }^{(11)}$, and two

Abbreviations: DIT, diet-induced thermogenesis; NPRQ, non-protein RQ; SMR, sleeping metabolic rate; TFEQ, Three Factor Eating Questionnaire; VAS, visual analogue scale.

*Corresponding author: Astrid Smeets, fax +31 433670976, email astrid.smeets@hb.unimaas.nl 
women dropped out because of personal reasons. The TFEQ factor 2 and 3 scores of all subjects were low and normal. Our primary interest was the effects on metabolism and substrate oxidation. We calculated the number of subjects needed based on the differences in RQ observed in a previous study investigating the effect of capsaicin on thermogenesis (see Table 1).

Eating behaviour was assessed using a validated Dutch translation of the TFEQ. Cognitive restrained and unrestrained eating behaviour (Factor 1), emotional eating and disinhibition (Factor 2) and the subjective feeling of hunger (Factor 3) were scored. All subjects were healthy, not taking medication, nonsmoking and not dieting. The habitual meal frequency of the subjects was three or more. All subjects consumed at least breakfast, lunch and dinner. All subjects gave written informed consent and the study was approved by the Maastricht University Ethics Committee.

\section{Study protocol}

The present study had a randomised crossover design and two experimental conditions. Subjects underwent two $36 \mathrm{~h}$ sessions in energy balance in a respiration chamber for measurements of energy expenditure and substrate oxidation. The subjects were given two or three meals per $\mathrm{d}$ in random order. The subjects did not follow a specific activity protocol. The two $36 \mathrm{~h}$ sessions were conducted 4 weeks apart to ensure that each subject was in the same phase of her menstrual cycle. Prior to each $36 \mathrm{~h}$ session ( $3 \mathrm{~d}$ before), subjects were provided with a diet in energy balance and with the same macronutrient composition (\% energy from carbohydrate 50, protein 35 , fat 15) at home. The subjects were instructed to eat the food provided, in three meals, for the $3 \mathrm{~d}$ before the experiment. The subjects entered the respiration chamber at 18.00 hours and subsequently received the dinner on the third day prior to the $36 \mathrm{~h}$ session. Subjects were instructed to go to bed around 23.00 hours. Dinner was served at 16.30 hours to make the protocol more convenient for the subjects. To keep the subjects in energy balance over $24 \mathrm{~h}$, the $24 \mathrm{~h}$ energy intake was compensated at dinner.

\section{Appetite profile}

Appetite profile was measured using anchored 100-mm visual analogue scales (VAS). During each respiration chamber session these questionnaires were completed before and after every meal on feelings of hunger, fullness, appetite, satiety, thirst, prospective food consumption and desire to eat. The scale was anchored from 'not at all' on the left to 'extremely'

Table 1. Calculation of number of subjects*

\begin{tabular}{ll}
\hline Mean of $\mathrm{HO}(\mu 1)$ & $0.83(\mathrm{RQ})$ \\
Mean of $\mathrm{Ha}(\mu 2)$ & $0.785(\mathrm{RQ})$ \\
Standard deviation of the population $(\sigma)$ & 0.035 \\
Significance level & 0.05 \\
Power & 0.90 \\
Two sided & $>\mathrm{HO} \neq \mathrm{Ha}$ \\
This led to a sample size of 14 subjects. & \\
$\quad$ We took a drop out of $10 \%$ into account, & \\
$\quad$ which made a total of $14+2=16$ subjects &
\end{tabular}

Source: Lejeune and co-workers ${ }^{(25)}$

${ }^{*}$ For details of subjects and procedures, see Subjects and methods. on the right. During each respiration chamber session, these questionnaires were completed before $(07.50$ hours $)$ and after (08.20 hours) breakfast, at 10.45 , before (12.00 hours) and after (12.20 hours) lunch, at 13.15 hours, at 14.15 hours, before (16.30 hours) and after (17.00 hours) dinner and on the next morning ( 08.00 hours). We extrapolated the data from the last measurement after dinner to the first measurement the next morning.

\section{Energy intake}

During each experimental session subjects were fed in energy balance. The energy content of the diet that the subjects consumed at home was based on BMR calculated with the equation of Harris-Benedict ${ }^{(12)}$ and multiplied by an activity index of $1.7^{(13)}$. In the respiration chamber, energy requirements were calculated based on sleeping metabolic rate (SMR) measured during the first night and multiplied by an activity index of $1.5^{(13)}$. Energy intake in the two meals condition was divided over the meals as $30 \%$ for breakfast $(08.00$ hours) and $70 \%$ for dinner (16.30 hours). In the three meals condition, energy intake was divided over the meals as $30 \%$ for breakfast (08.00 hours), $20 \%$ for lunch (12.00 hours) and $50 \%$ for dinner (16.30 hours). The macronutrient composition of each $24 \mathrm{~h}$ diet was $15 \%$ energy from protein, $35 \%$ energy from fat and 50\% energy from carbohydrates.

\section{Body composition}

Body composition was determined by underwater weighing in the fasted state. Body mass in air and under water was determined on a digital balance, accurate to $0.01 \mathrm{~kg}$ (Sauter type E1200). Lung volume was measured simultaneously with the He dilution technique using a spirometer (Volugraph 2000; Mijnhardt, The Netherlands). Body density was used to calculate body fat according to the two-compartment model with the equation of $\mathrm{Siri}^{(14)}$.

\section{Indirect calorimetry}

$\mathrm{VO}_{2}$ and $\mathrm{CO}_{2}$ production were measured in the respiration chamber ${ }^{(15)}$. The respiration chamber is a $14 \mathrm{~m}^{3}$ room, furnished with a bed, chair, computer, television, radio cassette player, telephone, intercom, sink and toilet. The room was ventilated with fresh air at a rate of 70-80 litres/min. The ventilation rate was measured with a dry gas meter (type 4; Schlumberger, Dordrecht, The Netherlands). The concentrations of $\mathrm{O}_{2}$ and $\mathrm{CO}_{2}$ were measured with the use of two paramagnetic oxygen analysers (Magnos 6G; Hartmann and Braun and type OA184A; Servomex, Crowborough, UK) and an IR $\mathrm{CO}_{2}$ analyser (Uras 3G; Hartmann and Braun, Frankfurt, Germany). During each 15 min period, six samples of outgoing air for each chamber, one sample of fresh air, zero gas and calibration gas were measured. The gas samples to be measured were selected by a computer that also stored and processed the data ${ }^{(15)}$.

\section{Energy expenditure and substrate oxidation}

Energy expenditure in $24 \mathrm{~h}$ consists of SMR, diet-induced thermogenesis (DIT) and activity-induced energy expenditure. From 08.00 hours on day 4 to 08.00 hours on day $5,24 \mathrm{~h}$ 
energy expenditure, its components and $24 \mathrm{~h}$ RQ were measured. Activity was monitored with a radar system based on the Doppler principle. SMR was defined as the lowest mean energy expenditure measured over 3 consecutive hours between midnight and 07.00 hours. DIT was calculated by plotting energy expenditure against radar output; both were averaged over $30 \mathrm{~min}$ periods. The intercept of the regression line at the lowest radar output represents the energy expenditure in the inactive state (RMR), which consists of SMR and DIT ${ }^{(16)}$. DIT was determined by subtracting SMR from RMR. Activityinduced energy expenditure was determined by subtracting SMR and DIT from $24 \mathrm{~h}$ energy expenditure. Physical activity level was calculated by dividing $24 \mathrm{~h}$ energy expenditure by RMR. Carbohydrate, fat and protein oxidation were calculated from the measurements of $\mathrm{VO}_{2}, \mathrm{CO}_{2}$ production and urinary $\mathrm{N}$ excretion by using the formula of Brouwer ${ }^{(17)}$. The non-protein RQ (NPRQ) was calculated using the formula:

$$
\left(\operatorname{VCO}_{2}(\mathrm{l} / \mathrm{d})-4.8 \times \mathrm{N}(\mathrm{g} / \mathrm{d})\right) /\left(\mathrm{VO}_{2}(\mathrm{l} / \mathrm{d})-6 \times \mathrm{N}(\mathrm{g} / \mathrm{d})\right) .
$$

The hours used for the calculation of the day NPRQ were 08.00 hours (first morning) - 20.00 hours and the hours used for the calculation of the night NPRQ were 20.00 hours -08.00 hours (second morning). Urine samples $(24 \mathrm{~h})$ were collected from the second void on day 4 until the first void on day 5. Samples were collected in containers with $10 \mathrm{ml} \mathrm{H}_{2} \mathrm{SO}_{4}$ to prevent $\mathrm{N}$ loss through evaporation. Volume and $\mathrm{N}$ concentration were measured, the latter with a $\mathrm{N}$ analyser (CHN-O-Rapid; Heraeus, Hanau, Germany).

\section{Fat oxidation}

Labelled fatty acids were obtained from Cambridge Isotope (Andover, MA, USA). Deuterium-labelled palmitic acid: d31-palmitic acid (DLM-215) was 98 atom\%. Deuterium labelled palmitic acid ( $20 \mathrm{mg} / \mathrm{kg}$ body weight) was added to chocolate milk, which was heated up to $65^{\circ} \mathrm{C}$ and consumed by the subjects at breakfast. Urine was collected for $24 \mathrm{~h}$ after breakfast. Recovery of the stable isotopes was calculated at $24 \mathrm{~h}$ post-dose according to the method described by Votruba $^{(18)}$. Cumulative recovery of deuterium from labelled palmitic acid (\%) over $24 \mathrm{~h}$ in the urine was used as a measure of dietary fat oxidation.

\section{Statistical analysis}

Data are presented as means and standard deviations unless otherwise indicated. Areas under the curve were calculated by using the trapezoid method. A Student's $t$ test (two-tailed distribution) was carried out to determine possible differences between the conditions. Significance was defined as $P<0 \cdot 05$. All of the statistical analyses were executed with Statview SE Graphics ${ }^{\mathrm{TM}}$ software (version 4.5; Abacus Concepts Inc, Berkeley, CA, USA).

\section{Results}

\section{Energy expenditure and substrate oxidation}

The results on $24 \mathrm{~h}$ energy expenditure are shown in Table 2. Total energy expenditure, DIT, activity-induced energy expenditure and SMR were not different between the two conditions. The $24 \mathrm{~h} \mathrm{RQ}$ and NPRQ were significantly lower in the three meals condition. When $24 \mathrm{~h}$ NPRQ was split into day (08.00 hours -20.00 hours) and night (20.00 hours - 08.00 hours), night NPRQ was significantly lower in the three meals condition. This indicates that $24 \mathrm{~h}$ fat oxidation was significantly higher in the three meals condition and that $24 \mathrm{~h}$ carbohydrate oxidation was significantly lower in the three meals condition (Table 2). Concerning the macronutrient balances (expressed as g eaten - $\mathrm{g}$ oxidized), however, no significant differences in fat, carbohydrate and protein balance were observed (Table 2).

Cumulative recovery of deuterium-labelled palmitic acid $(\%)$ over $24 \mathrm{~h}$ was significantly lower in the three meals condition compared with the two meals condition $(P<0.02$; Fig. 1), indicating that more fat from the breakfast was oxidised in the two meals condition than in the three meals condition.

\section{Satiety}

We present the VAS data on satiety; these data are representative for the scores on related questions, such as fullness, and inversely related to scores in hunger, desire to eat and prospective consumption. Satiety scores over the day are shown in Fig. 2. Between 07.50 hours and 12.00 hours, no differences in satiety scores between the three meals and two meals condition were observed. At 12.20, 13.15, 14.15 and 16.30 hours, satiety scores were significantly higher in the three meals condition than in the two meals condition $(P<0.05)$. After dinner and on the next morning no differences in satiety scores between the three meals and two meals condition were observed. Areas under the curves of satiety scores over $24 \mathrm{~h}$ were 1148 (SD 293) mm VAS $\times \mathrm{h}$ in the three meals condition and 988 (SD 197) $\mathrm{mm} \mathrm{VAS} \times \mathrm{h}$ in the two meals condition $(P<0.05$, Fig. 3).

\section{Discussion}

The present study shows metabolic effects of postponing a meal in the postprandial state. Eating three meals compared with two meals, and therefore decreasing inter-meal intervals, decreased RQ and increased $24 \mathrm{~h}$ fat oxidation, but had no effects on $24 \mathrm{~h}$ energy expenditure, DIT, activity-induced energy expenditure and SMR. The same amount of energy divided over three meals compared with over two meals increased satiety feelings over $24 \mathrm{~h}$. This was due to the smaller inter-meal interval, which resulted in significant differences in feelings of satiety during daytime. Cumulative recovery of deuterium-labelled palmitic acid (\%) over $24 \mathrm{~h}$, however, indicated that more dietary fat was oxidised when the inter-meal interval was larger. Dividing the same amount of energy over fewer meals, and therefore bigger meals, could theoretically lead to higher energy costs for the absorption, transport, conversion and storage of nutrients. Several meal frequency studies have observed no effect of meal frequency on $24 \mathrm{~h}$ energy expenditure ${ }^{(19)}$. Most studies, however, used a habituation period before testing the effect of the meal frequency on $24 \mathrm{~h}$ energy expenditure. A study with no habituation period by Verboeket-van de Venne \& Westerterp observed no acute effects of eating two or seven meals per $\mathrm{d}$ on $24 \mathrm{~h}$ energy expenditure ${ }^{(20)}$. In addition, previous studies 
Table 2. Total energy expenditure (TEE), components of energy expenditure, substrate oxidation, $R Q$ and percent cumulative recovery of deuterium labelled palmitic acid on a two meals $v$. a three meals per $d$ diet†

(Values are mean and standard deviations)

\begin{tabular}{|c|c|c|c|c|c|}
\hline & \multicolumn{2}{|c|}{ Two meals ( $n$ 14) } & \multicolumn{2}{|c|}{ Three meals ( $n$ 14) } & \multirow[b]{2}{*}{$P^{*}$} \\
\hline & Mean & SD & Mean & SD & \\
\hline $24 \mathrm{~h} \mathrm{RQ}$ & 0.88 & 0.03 & 0.86 & 0.04 & $<0.01$ \\
\hline 24 h NPRQ & 0.92 & 0.04 & 0.89 & 0.05 & $<0.01$ \\
\hline NPRQ day & 0.87 & 0.04 & 0.88 & 0.06 & NS \\
\hline NPRQ night & 0.95 & 0.06 & 0.87 & 0.05 & $<0.01$ \\
\hline $\mathrm{EI}(\mathrm{MJ} / \mathrm{d})$ & $9 \cdot 2$ & 0.5 & $9 \cdot 2$ & 0.5 & NS \\
\hline TEE (MJ/d) & $8 \cdot 2$ & 0.8 & 8.5 & 0.6 & NS \\
\hline DIT (MJ/d) & 0.86 & 0.23 & 0.90 & 0.30 & NS \\
\hline DIT (\% El) & $9 \cdot 43$ & $2 \cdot 58$ & 9.90 & 3.47 & NS \\
\hline $\mathrm{EB}(\mathrm{MJ} / \mathrm{d})$ & 0.90 & 0.56 & 0.68 & 0.50 & NS \\
\hline AEE (MJ/d) & 1.49 & 0.30 & 1.59 & 0.34 & NS \\
\hline SMR (MJ/d) & 5.93 & 0.56 & 5.98 & 0.47 & NS \\
\hline $\mathrm{PAL}$ & $1 \cdot 38$ & 0.08 & 1.42 & 0.08 & NS \\
\hline $24 \mathrm{~h}$ fat oxidation $(\mathrm{g})$ & $50 \cdot 2$ & $32 \cdot 4$ & $76 \cdot 3$ & $24 \cdot 7$ & $<0.01$ \\
\hline $24 \mathrm{~h}$ fat balance ( $\mathrm{g}$ eaten $-\mathrm{g}$ oxidised) & $23 \cdot 8$ & $27 \cdot 7$ & $31 \cdot 7$ & $20 \cdot 0$ & NS \\
\hline $24 \mathrm{~h}$ carbohydrate oxidation $(\mathrm{g})$ & $279 \cdot 6$ & $56 \cdot 8$ & $228 \cdot 6$ & $52 \cdot 9$ & $<0.01$ \\
\hline $24 \mathrm{~h}$ carbohydrate balance ( $\mathrm{g}$ eaten $-\mathrm{g}$ oxidised) & $9 \cdot 8$ & $62 \cdot 7$ & $13 \cdot 5$ & $56 \cdot 8$ & NS \\
\hline $24 \mathrm{~h}$ protein oxidation $(\mathrm{g})$ & $66 \cdot 1$ & $17 \cdot 4$ & $66 \cdot 6$ & $16 \cdot 9$ & NS \\
\hline $24 \mathrm{~h}$ protein balance ( $\mathrm{g}$ eaten $-\mathrm{g}$ oxidised) & 0.2 & $19 \cdot 9$ & $-8 \cdot 1$ & $18 \cdot 0$ & NS \\
\hline
\end{tabular}

NPRQ, non-protein quotient; El, energy intake; DIT, diet induced thermogenesis; EB, energy balance; AEE, activityinduced energy expenditure; SMR, sleeping metabolic rate; PAL, physical activity level.

* Student's $t$ test, two-tailed distribution.

†For details of subjects and procedures, see Subjects and methods.

have not observed effects of meal frequency on $\mathrm{DIT}^{(19)}$. In the present study, we measured the effect of meal frequency on DIT over $24 \mathrm{~h}$, which is much longer than most previous studies that have measured DIT up to $6 \mathrm{~h}^{(19)}$. Nevertheless, we observed no differences in DIT when equal energy intake was divided over three or two meals.

NPRQ was higher in the two meals condition compared with the NPRQ in the three meals condition. Chapelot et al. found a similar effect ${ }^{(10)}$. A 4-week habituation period in which subjects decreased their habitual meal frequency of four meals per $d$ to three per $d$ increased late night RQ. In the present study, most likely the increase in NPRQ, particularly during the night, in the two meals condition is a consequence of the relatively large meal that was consumed in the early evening. The large amount of carbohydrates and protein will preferentially be oxidised, because the body's capacity to store these macronutrients is limited. Fat is easily stored, since the body's capacity to store fat is practically unlimited. Carbohydrates are stored as glycogen in muscle and liver tissue. In the present study, bigger glycogen reserves may have been built up after dinner in the two meals condition. The bigger and therefore longer availability of oxidisable carbohydrates may have postponed the oxidation of fat, which resulted in the higher RQ over night in the two meals condition. We estimated that the physical activity level in the respiration chamber would be $1 \cdot 5$. We used this physical activity level to calculate energy intake. Their actual physical activity level was 1.38 in the two meals condition and 1.42 in the

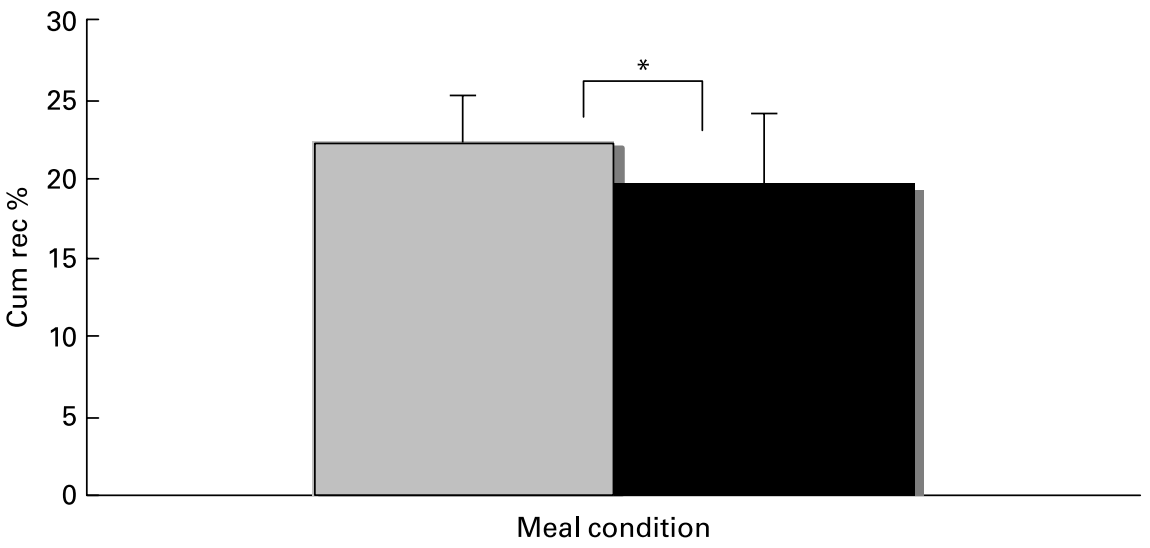

Fig. 1. Cumulative recovery (cum rec) of deuterium from deuterium labelled palmitic acid in the two meals condition ( $\square$ ) and the three meals condition ( $\square$ ). ${ }^{\star}$ Mean value was significantly different $(P<0.05)$. For details of subjects and procedures, see Subjects and methods. 


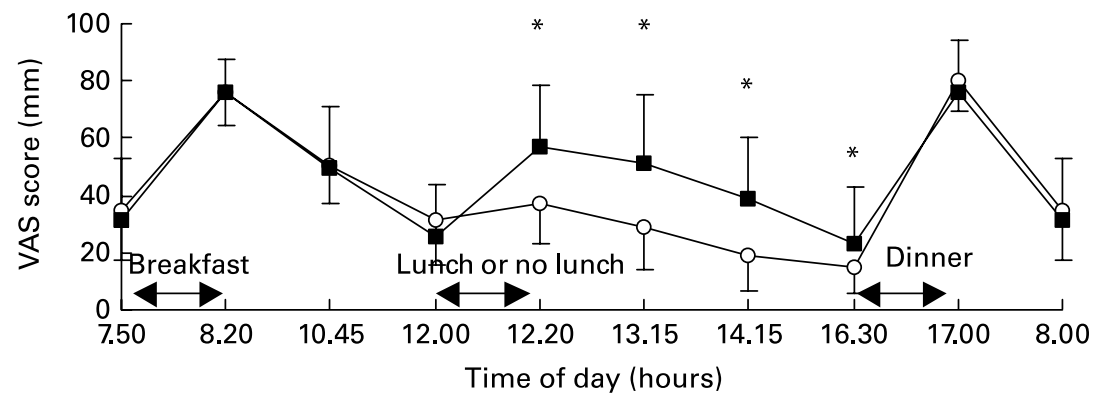

Fig. 2. Satiety visual analogue scale (VAS) scores over $24 \mathrm{~h}$ in the two meals condition (-O-) and the three meals condition (- $\mathbf{-}-)$. ${ }^{*}$ Mean values were significantly different $(P<0.05)$. For details of subjects and procedures, see Subjects and methods.

three meals condition. Therefore, during both conditions, the subjects were slightly in positive energy and fat balance. Despite this surplus of energy and fat, more fat was oxidised when energy intake was divided over three meals compared with over two meals. Based on the present results, it seems that spreading energy intake over the day in several meals may influence $24 \mathrm{~h}$ substrate oxidation beneficially. Westerterp-Plantenga et al. observed an inverse relationship between habitual meal frequency and the ability to compensate for a high fat preload $^{(21)}$. Young lean men with a habitually low meal frequency had a higher energy intake after a high fat $v$. a high carbohydrate preload than young lean men with a habitually high meal frequency. Observations from the latter study and the present study indicate that a low meal frequency could be detrimental because it may reduce fat oxidation, due to the postponed fat oxidation after a high carbohydrate load, and promote fat storage due to the lower ability to compensate for fat intake. Lower cumulative recovery of deuterium labelled palmitic acid indicates that less fat from the breakfast was oxidised in the three meals condition than in the two meals condition. This means that a greater proportion of the fat from the breakfast is stored before oxidation in the three meals condition. In the two meals condition, the inter-meal interval is much larger and therefore the body uses more fat from the breakfast directly instead of storing and remobilising it.

The $24 \mathrm{~h}$ satiety as well as satiety during the afternoon was positively affected when a meal was eaten at lunchtime. Increasing meal frequency has previously been shown to sustain satiety ${ }^{(7)}$. In the present study we observed an increase in $24 \mathrm{~h}$ satiety when the same amount of energy was eaten in three meals instead of two meals. This was obviously due to

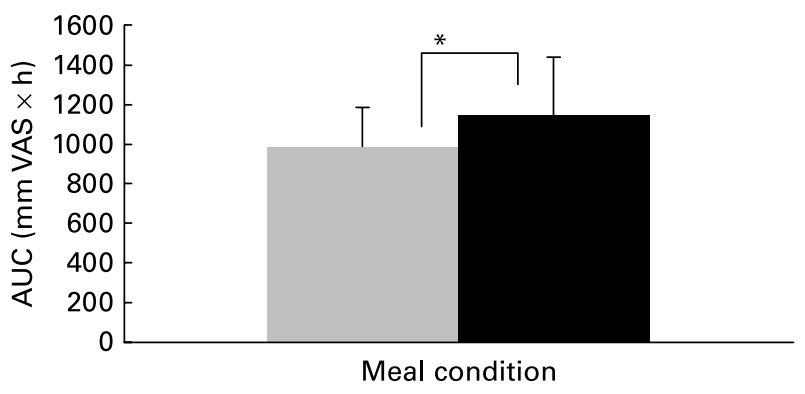

Fig. 3. Area under the curve (AUC) of satiety visual analogue scale (VAS) scores over $24 \mathrm{~h}$ in the two meals condition $(\square)$ and the three meals condition ( $\square)$. * Mean value was significantly different $(P<0.05)$. For details of subjects and procedures, see Subjects and methods. increased satiety after lunch in the three meals condition compared with decreased satiety after no lunch in the two meals condition. In order to sustain satiety, energy intake should take place during the day to synchronise in an optimal way with energy expenditure. Dinner containing $50 \%$ or $70 \%$ energy requirement appears not to cause differences in postmeal satiety. Mechanisms explaining the short-term effect of increased meal frequency on satiety may be related to substrate utilisation or satiety-related hormones. Increasing the number of meals per $d$ has been shown to flatten fluctuations in plasma glucose and insulin concentrations ${ }^{(22)}$. The pre-meal drop in plasma glucose concentrations, associated with feelings of hunger and meal initiation, may thus be prevented by a more frequent meal pattern. In a recent study, Jackson et al. studied the effect on gastric emptying of two isoenergetic meals $3 \mathrm{~h}$ apart or six isoenergetic meals fed hourly. Increased feeding frequency delayed the gastric emptying of a subsequent meal, but significant effects on postmeal appetite could not be demonstrated ${ }^{(23)}$. It can also be expected that meal frequency has an effect on gut-derived hormones such as glucagon-like peptide-1, ghrelin and peptide YY. More frequent exposure to nutrients may lead to a 'building up' of these hormones and subsequently have larger effects on hunger and satiety. Results of some of our recent studies suggest that effects of nutrients on plasma GLP-1 concentrations are more pronounced after multiple exposure compared with after one exposure $^{(24)}$ (AJ Smeets, S Soenen, ND Luscombe-Marsh and MS Westerterp-Plantenga, unpublished results).

Most meal frequency studies have studied effects on metabolism and appetite over a longer period of time and have compared high meal frequency (four to nine meals/d) with low meal frequency (one to three meals/d). In the present study, subjects were in an equal state of energy balance and started the test days with the same breakfast. This gave us the opportunity to compare effects of the size of the inter-meal interval on energy expenditure, substrate oxidation on satiety, without differences in energy balance as a confounding factor.

In healthy, normal-weight women, decreasing the inter-meal interval sustains satiety, particularly over the day, and sustains fat oxidation, particularly over night. Increasing meal frequency, and thereby decreasing inter-meal frequency, in a state of energy balance may be a useful tool to prevent large fluctuations in feelings of satiety and substrate utilisation. We studied a group of healthy, normal-weight women, who had a small range in BMI. Overweight and obese subjects should be studied in the same protocol to make the findings applicable to a broader population. The observed higher total 
fat oxidation in the three meals condition and the higher dietary fat oxidation in the two meals condition suggest that the inter-meal interval may play a role in the utilisation of substrates from different sources (stored or meal derived). Future studies should give insight into the role of inter-meal intervals in dietary fat oxidation and stored fat oxidation in relation to overweight.

\section{Acknowledgements}

We gratefully acknowledge Krista Morren, Maartje Spetter, Loek Wouters and Paul Schoffelen for their assistance. The research was sponsored by Top Institute Food and Nutrition, Wageningen, The Netherlands. None of the authors had any financial or personal interest in any company or organisation sponsoring the research.

\section{References}

1. Westerterp KR \& Elbers JHM (1999) Gender Differences, Energy Balance, and Effects of Sex Steriod Hormones on Circulating Leptin Levels. Milan, Italy: Edra, Medical Publishing \& New Media.

2. Westerterp KR \& Goran MI (1999) Age and Energy Balance. Milan, Italy: Edra, Medical Publishing \& New Media.

3. Fabry P, Hejl Z, Fodor J, Braun T \& Zvolankova K (1964) The frequency of meals. Its relation to overweight, hypercholesterolaemia, and decreased glucose-tolerance. Lancet ii, 614-615.

4. Hejda S \& Fabry P (1964) Frequency of food intake in relation to some parameters of the nutritional status. Nutr Dieta Eur Rev Nutr Diet 64, 216-228.

5. Fabry P, Hejda S, Cerny K, Osancova K \& Pechar J (1966) Effect of meal frequency in schoolchildren. Changes in weight-height proportion and skinfold thickness. Am J Clin Nutr 18, 358-361.

6. Westerterp-Plantenga MS, Wijckmans-Duysens NA \& Ten Hoor F (1994) Food intake in the daily environment after energy-reduced lunch, related to habitual meal frequency. Appetite 22, 173-182.

7. Speechly DP \& Buffenstein R (1999) Greater appetite control associated with an increased frequency of eating in lean males. Appetite 33, 285-297.

8. Zizza C, Siega-Riz AM \& Popkin BM (2001) Significant increase in young adults' snacking between 1977-1978 and 1994-1996 represents a cause for concern! Prev Med 32, 303-310.

9. Stote KS, Baer DJ, Spears K, et al. (2007) A controlled trial of reduced meal frequency without caloric restriction in healthy, normal-weight, middle-aged adults. Am J Clin Nutr 85, 981-988.
10. Chapelot D, Marmonier C, Aubert R, Allegre C, Gausseres N, Fantino M \& Louis-Sylvestre J (2006) Consequence of omitting or adding a meal in man on body composition, food intake, and metabolism. Obesity (Silver Spring) 14, 215-227.

11. Stunkard AJ \& Messick S (1985) The three-factor eating questionnaire to measure dietary restraint, disinhibition and hunger. J Psychosom Res 29, 71-83.

12. Harris JA \& Benedict FG (1918) A biometric study of human basal metabolism. Proc Natl Acad Sci U S A 4, 370-373.

13. Westerterp KR (1999) Exercise and Energy Balance. Milan, Italy: Edra, Medical Publishing \& New Media.

14. Siri WE (1956) The gross composition of the body. Adv Biol Med Phys 4, 239-280.

15. Schoffelen PF, Westerterp KR, Saris WH \& Ten Hoor F (1997) A dual-respiration chamber system with automated calibration. J Appl Physiol 83, 2064-2072.

16. Westerterp KR, Wilson SA \& Rolland V (1999) Diet induced thermogenesis measured over $24 \mathrm{~h}$ in a respiration chamber: effect of diet composition. Int J Obes Relat Metab Disord 23, 287-292.

17. Brouwer E (1957) On simple formulae for calculating the heat expenditure and the quantities of carbohydrate and fat oxidized in metabolism of men and animals, from gaseous exchange (Oxygen intake and carbonic acid output) and urine-N. Acta Physiol Pharmacol Neerl 6, 795-802.

18. Votruba SB, Zeddun SM \& Schoeller DA (2001) Validation of deuterium labeled fatty acids for the measurement of dietary fat oxidation: a method for measuring fat-oxidation in free-living subjects. Int J Obes Relat Metab Disord 25, 1240-1245.

19. Bellisle F, McDevitt R \& Prentice AM (1997) Meal frequency and energy balance. Br J Nutr 77, Suppl. 1, S57-S70.

20. Verboeket-van de Venne WP \& Westerterp KR (1991) Influence of the feeding frequency on nutrient utilization in man: consequences for energy metabolism. Eur J Clin Nutr 45, 161-169.

21. Westerterp-Plantenga MS, Kovacs EM \& Melanson KJ (2002) Habitual meal frequency and energy intake regulation in partially temporally isolated men. Int J Obes Relat Metab Disord 26, $102-110$.

22. Jenkins DJ (1997) Carbohydrate tolerance and food frequency. Br J Nutr 77, Suppl. 1, S71-S81.

23. Jackson SJ, Leahy FE, Jebb SA, Prentice AM, Coward WA \& Bluck LJ (2007) Frequent feeding delays the gastric emptying of a subsequent meal. Appetite 48, 199-205.

24. Lejeune MP, Westerterp KR, Adam TC, Luscombe-Marsh ND \& Westerterp-Plantenga MS (2006) Ghrelin and glucagon-like peptide 1 concentrations, 24-h satiety, and energy and substrate metabolism during a high-protein diet and measured in a respiration chamber. Am J Clin Nutr 83, 89-94.

25. Lejeune MP, Kovacs EM \& Westerterp-Plantenga MS (2003) Effect of capsaicin on substrate oxidation and weight maintenance after modest body-weight loss in human subjects. $\mathrm{Br} J$ Nutr 90, 651-659. 